\title{
Experimental study on the effect of alternator speed to the car charging system
}

\author{
Rozdman K. Mazlan ${ }^{1,}$, Reduan M. Dan ${ }^{1,2}$, Mohd Z. Zakaria ${ }^{1,2}$, Abdul H. A. Hamid ${ }^{1}$ \\ ${ }^{1}$ Faculty of Mechanical Engineering, Universiti Teknikal Malaysia Melaka, Hang Tuah Jaya, 76100 \\ Durian Tunggal, Melaka, Malaysia. \\ ${ }^{2}$ Centre for Advanced Research on Energy, Universiti Teknikal Malaysia Melaka, Hang Tuah Jaya, \\ 76100 Durian Tunggal, Melaka, Malaysia.
}

\begin{abstract}
In this paper, we present our work, which is doing an energy audit on alternator's current output and battery's voltage based on alternator speed. Up until today, the demand for power in automobile is ever increasing. As technology advances, more and more electrical devices were produced and being installed in vehicles. To cope with the demand, alternator has been designed and modified so that it can produce enough power. This research is to study the effect of alternator speed to the charging system. The car used in this experiment is Proton Preve 1.6 Manual. In both ISO 8854 and SAE J 56, alternator testing and labelling standards indicate that the rated output an alternator is the amount of current that it is capable of producing at 6,000 RPM. Three different constant speed of engine which is 750 RPM as idle speed, 1500 RPM and 3000 RPM as cruise speed were taken as parameter. The speed of the alternator was measured using tachometer, digital multi-meter was used to measure battery's voltage, and AC/DC Clamp was used to measure alternator current output. The result shows that the faster the alternator spin, the more power it can produce. And when there is more power, the faster the charging rate of the battery.
\end{abstract}

\section{Introduction}

In our modern world, electricity plays a pivotal role in driving industry and powering the systems used to meet our agricultural, health care, educational, and commercial needs. Among the among impacted industry is the automobile industry. The electrical power demands or requirements in vehicle transportation have been rising rapidly for many years and are expected to continue to rise (Fig. 1). This flow of direction is driven by the replacement of engine-driven loads with electrically-powered versions, and by the introduction and establishment of a wide range of new functionality in vehicles [1]. The continuous increase in power requirements is pushing the limits of typical and traditional automotive power generation and control technology, and is motivating the development of both higher-power and higher-voltage electrical systems and components [2].

\footnotetext{
${ }^{*}$ Corresponding author: rozdman.edir@gmail.com
} 


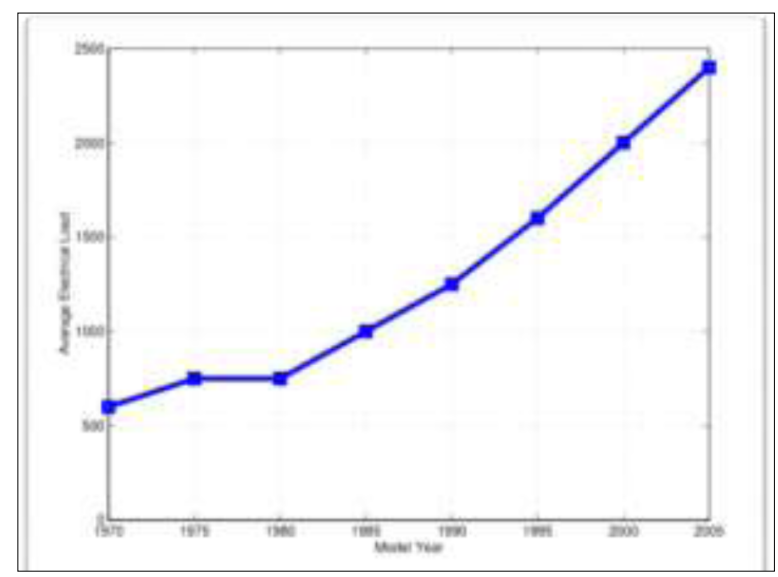

Fig. 1. Automotive electrical power requirements [1].

One of the machine that has been through many process of improvement in the automobile industry is the alternator. Alternators are all around us. It is almost impossible or hardly an engine which does not have an alternator, or maybe more, running alongside in cars, trucks, buses, recreational vehicles, boats, aircraft, farm machines, earth moving equipment, and all kinds of stationary engines. Clear as the daylight, the alternators are doing their job very well since we hear so little about them. Well, some of us may not know what an alternator is. And if something does go wrong, most of the more popular models have their replacement available almost instantly, waiting on dealer shelves, in alternator shops, often even in department stores [3].

Every automobile has a charging system. For a car, it consists of the alternator, regulator, and the interconnecting wiring. Charging system act as main source of electrical energy, and provide power to electrical components in the car while the engine is running. If there is no charging system, battery will be the source of power. But until the battery is weak, and there is no power source to charge the battery, then this will cause the engine to has less current to fire the spark plugs. In this case, the engine will be forced to stop running.

The use of an increasing number of electrically operated or actuated accessories is increasing the power demand from the alternator. The loads include electrically heated windows, seats, and catalysts; motors for cooling fans (and possibly coolant pumps); and electric actuators for power steering, seat adjustment, and possibly brakes. In 1990, a typical requirement was $500 \mathrm{~W}$. Today, it is 1 to $1.5 \mathrm{~kW}$, and by 2005 , it is forecast to be approximately $3 \mathrm{~kW}$ [4]. With a $12 \mathrm{~V}$ system, $3 \mathrm{~kW}$ would require a current of 250 amps. Modern and latest car nowadays has been equipped with more electrical devices, or simply said, wide range of functionality. Devices such as DVD player, rear camera, USB port for phone charging, LED light, etc. All these devices require more power to be generated by the alternator. Conventional alternator may only produce power for about 500 Watt to 600 Watt. But nowadays, a single alternator can produce power up to 2500 Watt, depending on the power demand.

The power that can be produced by an alternator is determined by the alternator rating. The output of the alternator ranges from $40 \mathrm{Amp}$ up to $120 \mathrm{Amp}$. For high-amp alternator, it can generate up to $300 \mathrm{Amp}$. Commercialized alternator is usually $12 \mathrm{~V}$. For some systems, especially for high power system, the alternator varies from $24 \mathrm{~V}$ up to $48 \mathrm{~V}$. The input of the alternator is speed dependents. It means that, the higher the speed of rotation of the alternator shaft, the more power the alternator produce. But vice versa, the output of the 
alternator is demand dependents. The alternator will only give out power depending on the demand from the system.

Most cars, while the engine is running, have a charging system that will generally produce a voltage between 13.5 and 14.4 volts. The charging system needs to produce more voltage than the battery rated voltage in order to overcome the internal resistance of the battery [5]. This is due to the fact that the current needed to recharge the battery would not flow at all if the charging system's output voltage was on par with the battery voltage. The charging rate will be faster if there is a greater difference of potential (voltage) between the battery's voltage and the alternator's output voltage [6].

For battery charging to occur, the alternator's voltage must exceed the battery's voltage. Alternator may not generate sufficient charging voltage until alternator speed is greater than about 2000 RPM. Typically, alternators have their full output rated at 6000 RPM but can continue to spin up to 12,000 RPM or more without any additional increase in output. The speed of an alternator is different for different type of car. The speed of an alternator depends on the speed of the engine. For a racing car, the ratio speed between engine and alternator is usually $1: 1$. For a drag car, the ratio is usually $1: 2$. And for street use, the ratio is usually $1: 3$.

When voltage causes current to flow, energy is converted. This is described as power. The unit of power is the watt [7]. As with Ohm's law, any one value can be calculated if the other two are known.

$$
\begin{aligned}
& \text { Power }=\text { Voltage } X \text { Current } \\
& \mathrm{P}=\mathrm{VI} \text { or } \mathrm{I}=\mathrm{P} / \mathrm{V} \text { or } \mathrm{V}=\mathrm{P} / \mathrm{I}
\end{aligned}
$$

A vehicle charging system has been represented in Figure 2 as three blocks, i.e. the alternator, battery, and vehicle loads. When engine is not running, the alternator voltage is less than the battery voltage so current flows from the battery to the vehicle loads and the alternator diodes prevent current flowing into the alternator. When engine is running, the alternator output is greater than the battery voltage, so current flows from the alternator to the vehicle loads as well as the battery. This implies that alternator output voltage must always be above the battery voltage during operation of the engine. However, the actual voltage used is critical and depends on a number of factors [8].

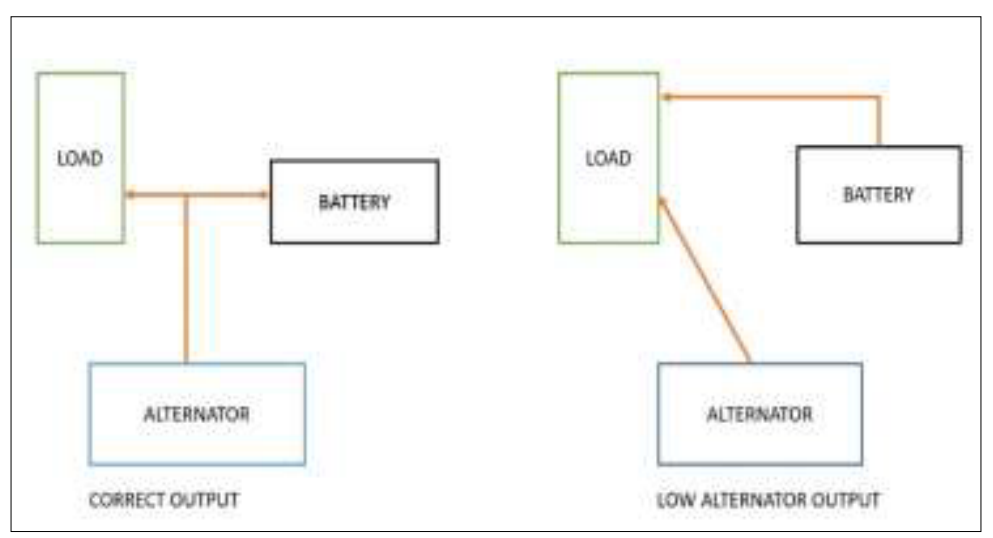

Fig. 2. Block diagram representing the vehicle charging system.

The relationship between alternator speed and alternator current is shown in Figure 3. The current output of the alternator is speed-dependent. The speed of the alternator depends 
on the turns ration ranging from 1:2 to 1:3 (crankshaft to alternator). The greater the speed, the greater the output. The rated current is output at an alternator speed of 6000 RPM [9].

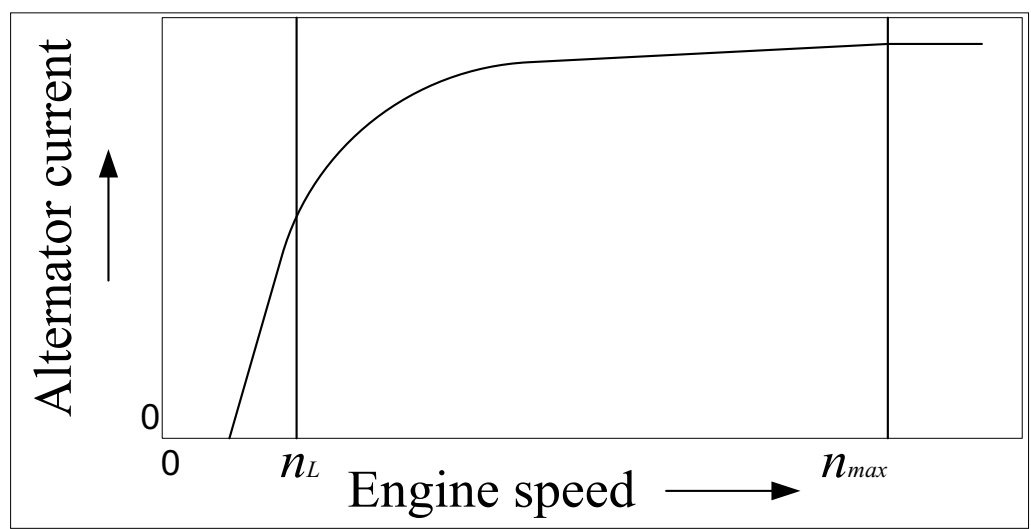

Fig. 3. Characteristic curve at maximum alternator current at constant voltage [9].

While the relationship between charging current, charging time, charging voltage, and alternator speed is shown in Figure 4 and Figure 5. The higher the current, the faster the charging rate of battery. When the current generated is greater than the current demand, then only the battery will start charging [10].

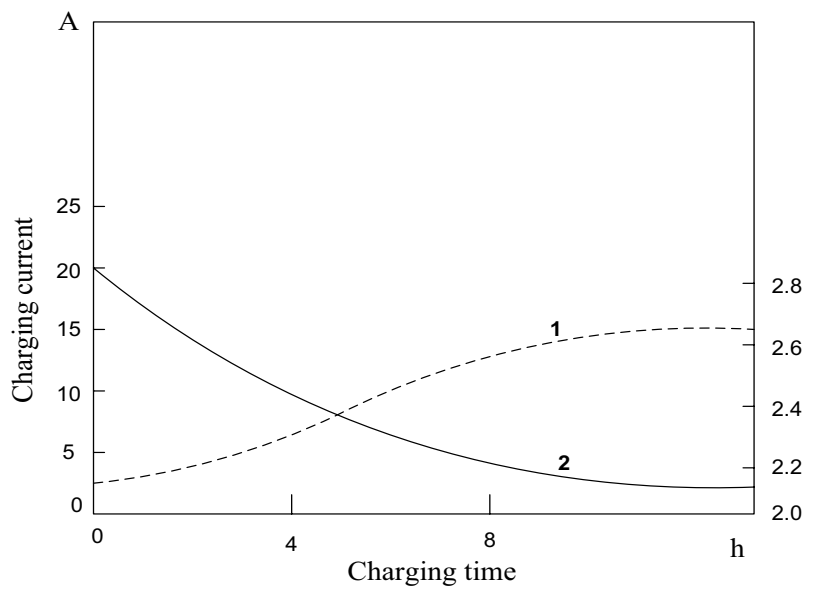

Fig. 4. Battery charging [10].

The purpose of this research is to find out the possibility of creating regenerating system to power added system to the car by channellings the unused current or excessive current from the alternator. In doing so, experiments needed to be done to find the relationship between alternator speed and the power it can produce, with the assists and knowledge gained from educational materials. 


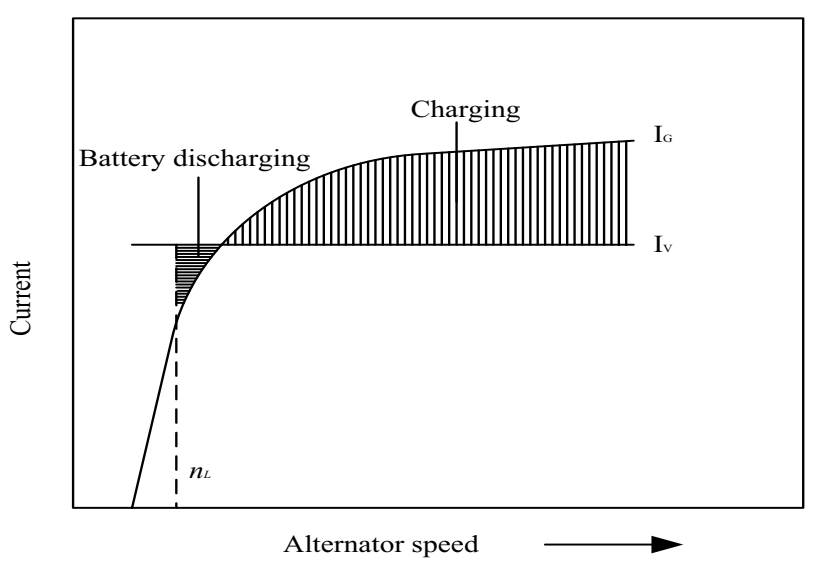

Fig. 5. Alternator output $I_{G}$ as a function of alternator speed [10].

\section{Experimental setup}

\subsection{Design of experiment}

The car used as experimental study object is Proton Preve 1.6 Manual. The alternator of the car has a rating of $90 \mathrm{~A} 12 \mathrm{~V}$. No modification is done to the car, especially the alternator. And no extra electrical devices were added. Only stock items were being used. The schematic diagram of the experimental study is shown in Figure 6. Car's battery and alternator are being tested first before continuing with the experiment to make sure they are in good condition and fully functioning.

A digital multi-meter was used to measure the voltage value of the battery. A tachometer was used to measure the speed of the alternator. Timing Light is a device which was used to measure the speed of the engine by clamping its clamp onto one of the cable at spark plug inlet. An AC/DC Clamp was used to measure the value of DC current at the alternator output.

The speed of the alternator and the speed of the engine was measured and compared to get the speed ration. This method is a lot easier compare to the method which one needs to measure the diameter of the alternator shaft and the diameter of the engine shaft to get the speed ration. The alternator is driven by the engine.

\subsection{Experimental procedure}

The parameters of the experimental study are alternator speed (RPM), DC current value form alternator output (Amp), and battery voltage value (V). Three different speed of engine has been set constant, which are 750 RPM as idle speed, 1500 RPM and 3000 RPM as cruise speed. Car's battery and alternator are being tested first before continuing with the experiment to make sure they are in good condition and fully functioning. A fully charged battery should read over 12.6 volts. The actual output voltage produced by the alternator will typically be about $1-1 / 2$ to 2 volts higher than battery voltage. At idle, most charging systems will produce 13.8 to 14.3 volts with no lights or accessories on. 


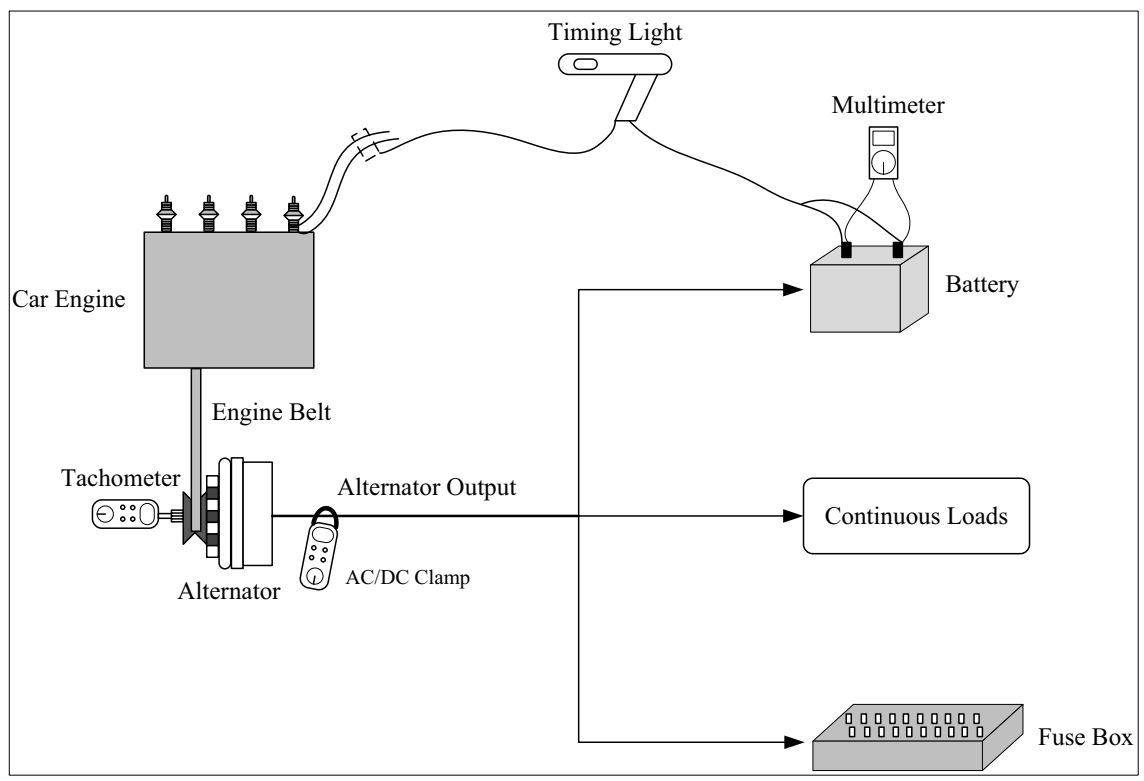

Fig. 6. Schematic diagram of experiment setup.

Table 1 shows the electrical components in the car. The electrical components acted as load to the alternator. The electrical components were turned on one by one in sequences. These steps applied to all three different speed. The value of current at alternator output and battery voltage was taken after each time the electrical component was turned on.

Table 1. Proton Preve electrical component.

\begin{tabular}{cc}
\hline No & Electrical components \\
\hline 1 & Radio \\
2 & Air-cond \\
3 & Front lamp \\
4 & Hi-beam \\
5 & Fog light \\
6 & Rear lamp (brake) \\
7 & Hazard, wiper \\
8 & Interior lamp \\
9 & Radiator fan \\
\hline
\end{tabular}

After all the available electrical components had been turned on, and the measurement has taken, all of the electrical components were turned off, and leave the car idle for five minutes. The speed remained constant. After five minutes, the battery voltage was measured again.

Every time before switch to new alternator speed, the battery needed to be sure that it has fully charged. 


\section{Results and discussion}

\subsection{Experiment data}

Table 1 shows the available electrical devices in Proton Preve 1.6 Manual. All the electrical devices were turned on and act as load to the alternator. The sequence has been set to ensure accuracy and consistency of the result. Table 2 is the measured speed of alternator and crankshaft. Table 3 shows the voltage reading of the battery after all the electrical components had been turned off for 5 minutes. The purpose is to study the relationship between current and charging rate of the battery.

Table 2. Speed difference between engine and alternator.

\begin{tabular}{cc}
\hline $\begin{array}{c}\text { Engine speed } \\
\text { (RPM) }\end{array}$ & $\begin{array}{c}\text { Alternator speed } \\
\text { (RPM) }\end{array}$ \\
\hline 750 & 1560 \\
1500 & 3150 \\
3000 & 6100 \\
\hline
\end{tabular}

Table 3. Battery voltage value after five minutes after all the electrical components turned off.

\begin{tabular}{cc}
\hline $\begin{array}{c}\text { Engine speed } \\
\text { (RPM) }\end{array}$ & Battery voltage (V) \\
\hline 750 & 13.1 \\
1500 & 13.7 \\
3000 & 14.0 \\
\hline
\end{tabular}

\subsection{Analysis}

The result of the experiment is as shown in Fig. 7.

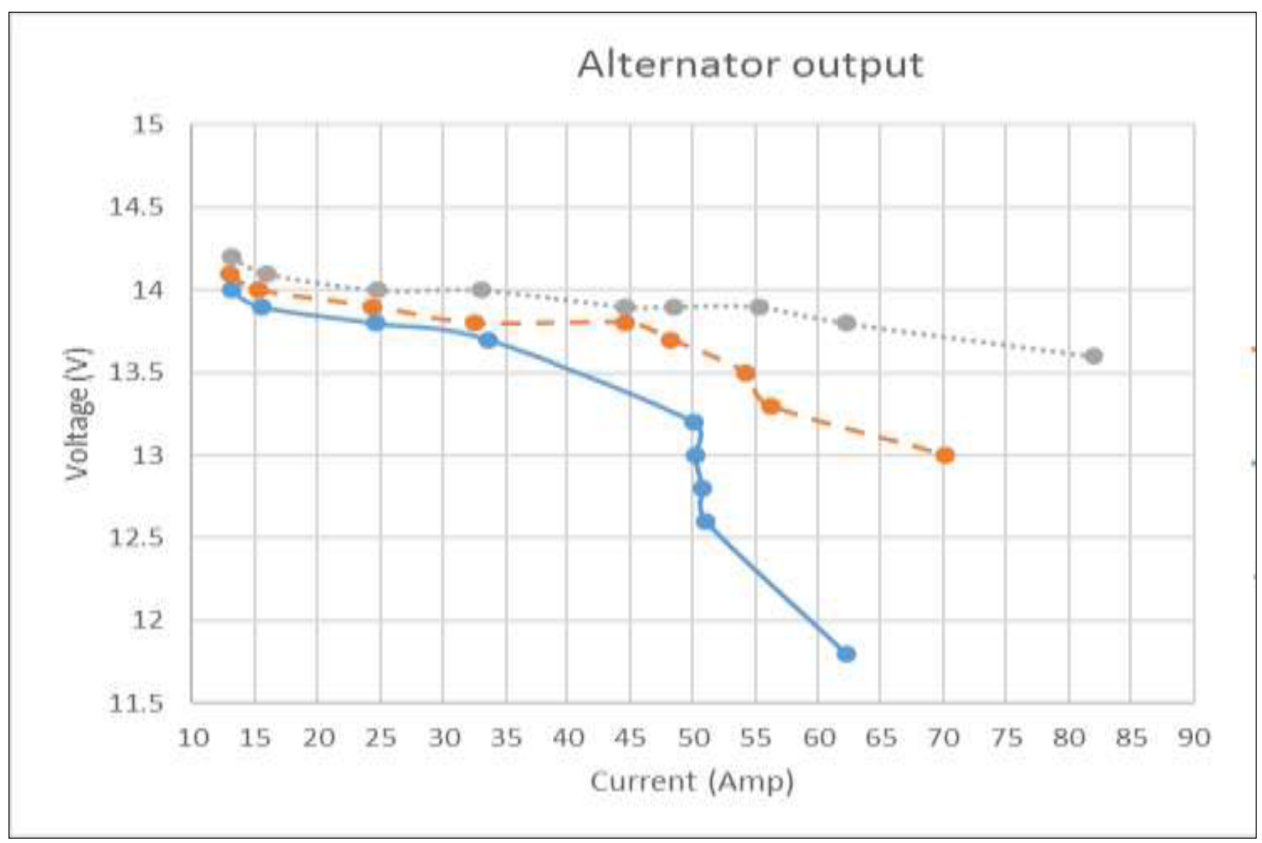

Fig. 7. Graph of battery voltage against alternator output current for engine speed 750 RPM (straight line), 1500 RPM (dashed line), and 3000 RPM (dotted line). 
From the data shown in Table 2, it shows that the alternator has a speed ration of 2:1 to the engine. It means, the speed of the alternator is twice the speed of the engine. Different car has different alternator-engine speed ration, depending on the suitability of the system. Normally, the speed ration has been set so that the alternator can produce enough power according to the car demand. The current output of the alternator is speed-dependent. For an engine idling speed, the alternator can only supply some of its rated current if it has a conventional turns ration ranging from 1:2 to 1:3 (crankshaft to alternator). By definition, the rated current is output at an alternator speed of 6000 RPM.

Based on the graph shown in Figure 7, it tells that the higher the speed of the alternator, the more power it can produce as proved in Figure 3. But as the alternator output current increase, the battery voltage drops. This means that the battery is not receiving enough power for recharge. A fully charging battery should have a voltage reading above $13.7 \mathrm{~V}$. When the battery is receiving low power, it will take more time to be fully charged. The slower the speed of the alternator, the more voltage drops significantly as the current increase. Power $(\mathrm{P})$ is measured in watts $(\mathrm{W})$, or for high power in kilowatts $(\mathrm{kW}) .1 \mathrm{~kW}$ is equal to $1000 \mathrm{~W}$. Power used by an electrical device is easily calculated. Just take the voltage across the device and multiply that by the current through it. Power $=$ voltage $\mathrm{x}$ current [7].

At current load 10 Amp to $35 \mathrm{Amp}$, the voltage drop for all three different speed are only slight different. The behaviour starts to change at current load more than $35 \mathrm{Amp}$. This can be said that the alternator can provide steady power for current below than $35 \mathrm{Amp}$ even at the slowest speed. Speed of the alternator influence the power capability it can supply. At low speeds, the alternator can't satisfy the combined load and the shortfall would usually be supplied by the main battery. But this is not necessary true, as the alternator still can supply the demand, but not at full. Only if the demand is exceeding the alternator rating, then only would the battery start to supply power.

All the electrical components still functioning, and the engine still running and not lugging down. But in term of Power (watt), there was decrease in value. Alternator cannot provide maximum power required, but still can function at minimum power required. The car will still run, but it is noticeable that the headlights get progressively dimmer. This is a sign that the battery is not fully charge. This may cause difficulty to start the engine later as there will be not enough power to spark the engine.

Alternator supply all the current demand for the electrical devices, while at the same time charging the battery. Table 3 shows the battery voltage value after all the electrical devices being turned off and be left for five minutes. A full charged battery should has a reading of $14.2 \mathrm{~V}$ to $14.4 \mathrm{~V}$. Here, based on Table 3, it shows that the higher the speed of alternator, the closest the voltage value of battery to fully charged value after five minutes. The faster the speed of alternator, the faster it is the rate of charging. And also, the faster the transfer or the moving of electron in the system. The faster the speed of the alternator, the faster the battery will be fully charged. As shown in Table 3, at idle speed 750 RPM, even after 5 minutes, the voltage reading was nowhere near the fully charged value. A battery voltage reading of $13.7 \mathrm{~V}$ and above while the engine is running is consider as good. But a battery voltage reading of $14.0 \mathrm{~V}$ and above is better.

When the engine is running, the alternator supplies electricity which, depending on the voltage level in the vehicle electrical system (determined by the alternator speed and the consumers drawing current), is normally enough to power the consumers and charge the battery as well. If the equipment current draw in the vehicle electrical system is greater than the alternator current (when engine is idling), the battery is discharged. The vehicle system voltage falls to the voltage level of the battery from which current is drawn. If the equipment current draw is less than the alternator current output, a proportion of the current 
flows to the battery and acts as a battery charging current. The vehicle system voltage increases to the set-point value specified by the voltage regulator.

The current output of the alternator is speed-dependent. For an engine idling speed, the alternator can only supply some of its rated current if it has a conventional turns ration ranging from 1:2 to $1: 3$ (crankshaft to alternator). By definition, the rated current is output at an alternator speed of 6000 RPM.

The electrical consumers have a variety of switch-on durations. A distinction is made between continuous loads, long-time loads, and short term loads. The electrical load requirements encountered during vehicle operations are not constant.

In vehicle electrical systems, the battery is charged using voltage limitation, where the battery charge current reduces automatically as the steady-state voltage rises. This prevents damage due to overcharging, and makes sure that the battery has a long service life. Battery charger, the alternator, on the other hand, still operates using constant current. Once the full state of charge has been reached, charging continues with only a slightly reduced, or possibly a constant current. Shortly after discharging begins, the voltage in the storage battery drops to a value which only changes relatively slowly if discharging continues. Battery discharge over a period of time, even if it is not subjected to loads. In other means, when no electrical equipment is connected.

The alternator must furnish the vehicle electrical system with a sufficient supply of current under all operating conditions in order to ensure the state of charge in the battery is always maintained at an adequate level. This is to ensure that the amount of current generated by the alternator under actual operating conditions is at least equal to the consumption of all electrical equipment within the same period.

Typical ratios in the passenger car sector lie between 1:2.4 and 1:3, in the commercial vehicle sector up to 1:5. In extreme cases like commuter traffic, the alternator runs for up to two-thirds of the total switch-on duration when the engine is idling, which is in the speed range with the lowest performance efficiency.

\section{Conclusions}

In this paper, the experiment was done to prove the theories, and to find the relationship between alternator speed and the charging system. The experiment was aimed to gain better understanding and better knowledge about charging system. The result shows that the faster the alternator, the more power it can produce. And when there is more power, the faster the charging of battery as the power to be supplied to other electrical consumer is more than enough. Current is inverse with voltage. When the alternator current is high at low speed, battery voltage will drop, and will need more time to get fully charged. But when alternator output current is low at low speed, the battery voltage is high as the battery get enough power for recharging. The Proton Preve used in the experiment has a crankshaft-alternator speed ratio of 1:2. At idling speed, the alternator still manages to supply the current demand from all the consumers, but has to reduce the current needed by the battery to get fully charge. As the speed of the alternator increase, it supplies more current to the consumers thus increase performance efficiency. Although Figure 7 shows that there is a decreases of battery voltage at $34 \mathrm{~A}$ and sudden drop of battery voltage at $50 \mathrm{~A}$ at idle speed, which cause by the increase of loads to the alternator and leads to low charge of battery, but in reality, this situation is rarely happen. In reality, most driver only turn on less equipment in the car such as radio, air-cond, and lights during night. All these only take up to $40 \mathrm{~A}$ of current, and the alternator can afford the demand and still can fully charge the battery even at idle speed. 
The authors would like to be obliged to to Kementerian Pengajian Tinggi for providing financial assistance, and to Fakulti Mekanikal, Universiti Teknikal Malaysia Melaka for providing laboratory facilities under project no FRGS/1/2014/TK06/FKM/02/F00209.

\section{References}

1. J. M. Miller, "Multiple voltage electrical power distribution system for automotive applications," in Proc. 31st Intersociety Energy Conversion Engineering Conference (IECEC), Washington, DC, Aug. (1996).

2. J. M. Miller, D. Goel, D. Kaminski, H.-P. Schoner, and T. M. Jahns, "Making the case for a next generation automotive electrical system," in Proc. IEEE-SAE International Conference on Transportation Electronics (Convergence), Dearborn, MI, Oct. (1998).

3. Edgar J. Beyn, "The 12 Volt Doctor's Alternator Book", C. Plath North American Division, Spa Creek Inc, Annapolis, Maryland. (1986).

4. Smith, M. "It's Volts That Counts," in Automotive Engineering, Vol. 26, No. 9,2001, pp. 52-55. (2001).

5. Paul Brand, "Chapter 4 Alternator Charging System," in How To Repair Your Car, Motorbook International, pp. 61, (2006).

6. "Charging System Basic" Retrieved from http://www.bcae1.com/charging.htm [Last access 6 June 2016]

7. Stewart Robertson, Chapter 3, Predicting Circuit Behaviour, in Automotive Electrical Maintenance. Oxford, Elsevier, pp. 30, (1994)

8. Dr. N.K. Giri, "Automobile Mechanical," New Delhi, Khanna Publisher, pp. 376, (2009).

9. Bosch, Automotive Handbook, $7^{\text {th }}$ Edition, Wiley, England, pp. 1009, (2007).

10. SAE International, Automotive Handbook, $8^{\text {th }}$ Edition, Robert Bosch, Plochigen, pp. 952-968, (2011). 